\title{
Nasal supratip pilonidal sinus: a rare manifestation
}

\author{
Firamir Bin Zulkifli ${ }^{1 *}$, Farah Dayana Bintin Zahedi ${ }^{2}$, Ahmad Bin Nordin ${ }^{1}$, Yong Doh Jeing ${ }^{1}$
}

Department of Otorhinolaryngology and Head and Neck Surgery, ${ }^{1}$ Queen Elizabeth Hospital, Kota Kinabalu, Sabah, ${ }^{2}$ University Kebangsaan Malaysia Medical Centre, Kuala Lumpur, Malaysia

\author{
Received: 15 April 2019 \\ Revised: 02 July 2019 \\ Accepted: 11 July 2019

\section{*Correspondence:} \\ Dr. Firamir Bin Zulkifli, \\ E-mail: firamirable@yahoo.com
}

Copyright: (C) the author(s), publisher and licensee Medip Academy. This is an open-access article distributed under the terms of the Creative Commons Attribution Non-Commercial License, which permits unrestricted non-commercial use, distribution, and reproduction in any medium, provided the original work is properly cited.

\begin{abstract}
Pilonidal sinus is widely associated with disease involving the gluteal cleft. Derived from the Latin word (Pilus=hair; nidus=nest), it was first described by Herbert Mayo in 1833. The pathognomonic finding of the pilonidal sinus is the presence of loose hairs in the sinus tract or cavity. We report a case of a fit middle age policeman who developed an unusual chronic discharging sinus over the tip of the nose. A computed tomography (CT) sinogram showed a localized blind subcutaneous tract over the nose. The course of management is discussed with reference to other reported works of literature. The patient was diagnosed to have a subcutaneous sinus over the tip of the nose with the aid of CT sinogram. Surgery was performed to excised the sinus tract through external rhinoplasty approached. Histopathological examination confirmed a sinus tract lined by keratinized stratified squamous epithelium with a tuft of hair. Patient was follow up for another year with no evidence of recurrence.
\end{abstract}

Keywords: Pilonidal sinus, Nasal supratip, External rhinoplasty

\section{INTRODUCTION}

Pilonidal disease of the post anal region rose to prominent during World War II when 78924 patients were admitted and treated in the Army Hospital. ${ }^{1}$ This condition is encountered most often in young adult hirsute men, often situated in the midline. Like the classical pilonidal sinuses of the gluteal cleft, the sinus over the nasal region is commonly asymptomatic until it becomes infected. Acute infected pilonidal sinus presents similarly to localised, superficial abscess in other locations. Paulose et al report a case of a young gentleman who developed a discharging sinus over the dorsum of the nose which was preceded by a trauma. ${ }^{1}$ Sreedharam et al reported a lesion highly resembling a pilonidal sinus over the nasal pyramid but there seem to be a diagnostic dilemma to distinguished it from a nasal dermoid. $^{2}$ Junaid et al reported 2 cases of pilonidal sinus involving the nasal bridge with both giving similar to complain of intermittent discharging sinus over the nasal bridge. $^{3}$ At the end of the 19th century, many authors considered pilonidal sinus to be of congenital origin. However, Patey and Scarfe in 1946 challenged the theory and hypothesized that the disease was acquired by the penetration of hair into the subcutaneous tissue with consequent granulomatous reaction. ${ }^{4-6}$ This theory is further substantiated by a study done by Karydakis in 1992 involving 6545 cases of pilonidal sinus who underwent advancing flap operation with the objective is to prevent external hair insertion which proved to be a success as the entire case were follow up without recurrence of disease. ${ }^{6}$ Comparable to sinuses in other locations the primary treatment is complete excision. During the acute phase, a broad-spectrum antibiotic is adviced. The occurrence of this sinus over the nasal pyramid is very rare and may lead to a diagnostic confusion and subsequent mismanagement. Hence, we share this case report for a better understanding of the disease. 


\section{CASE REPORT}

A 42-year-old policeman with no medical history presented with a chronic discharging sinus over the tip of the nose. He had unattended nasal trauma 20 years ago. He was hit by a sharp shellfish over the nose which bleeds scantily with minimal pain. Over the years, a small sinus developed over the nose with occasional troublesome discharge. There is a slight depression over the tip of the nose. Examination revealed a sinus opening at the supratip area of the nasal dorsum, which on digital pressure produced little purulent discharge. A rigid nasoendoscopic examination did not reveal any communication with the sinus. The purulent discharge was sent for culture with a result showing no organism growth. A CT Sinogram revealed a midline blind subcutaneous tract which ends just distal to the nasal bone. There is no extension of the tract intracranially which reduced the possible diagnosis of nasal dermoid. On the basis of subcutaneous sinus, the patient was scheduled for surgery. A planned external rhinoplasty was performed and an elliptical incision is made over the sinus opening. The external rhinoplasty incision started at the columella and extended marginally. An injection of methylene blue was administered over the sinus to guide the excision. This provides a good exposure of the tract and allows for an en bloc removal. During the operation, a tuft of hair was found within the sinus tract. The sinus tract which measures $2.5 \mathrm{~cm}$ along with the tuft of hair was removed as a whole. Postoperatively patient was put on antibiotics. Suture removal was done on the seventh postoperative day and the patient was discharged. The post-operative period was uneventful and the end results are apparent. He remains symptom free after the operation with no evidence of any recurrence. Histopathological examination revealed a tract lined by keratinized stratified squamous epithelium containing a tuft of hair. Deep to the tract, multiple clusters of sebaceous glands and hair follicles are present.

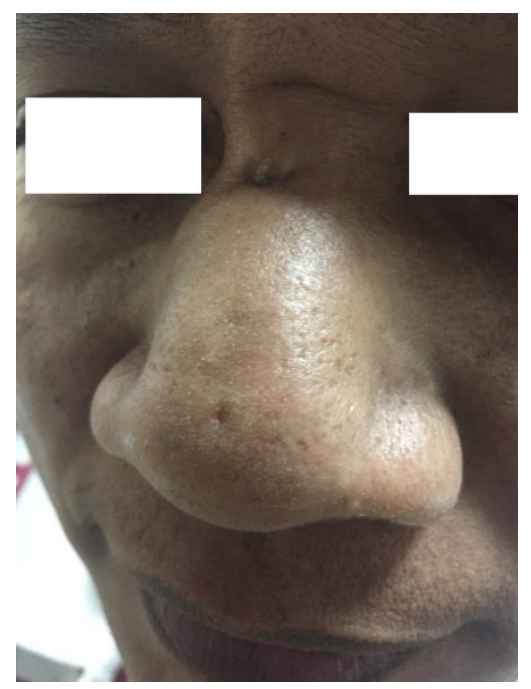

Figure 1: Clinical photograph of the patient showing a sinus opening over the nasal dorsum.

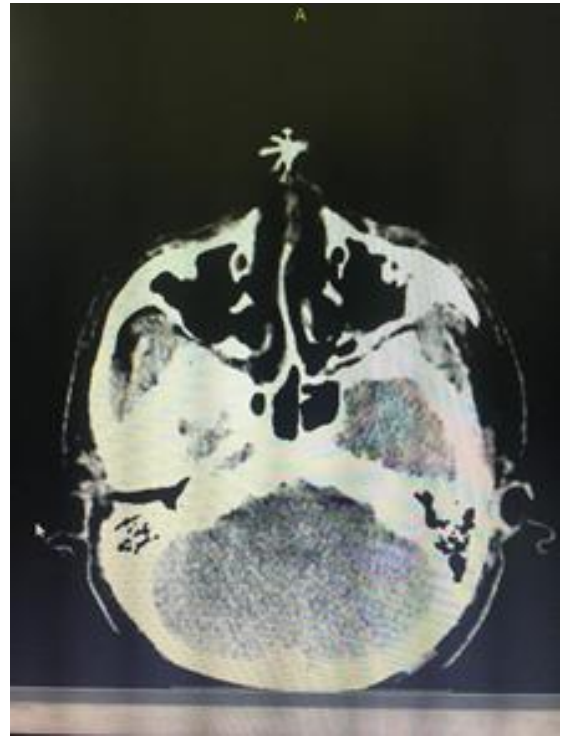

Figure 2: CT sinogram showing a blinded sinus tract with branching tract.

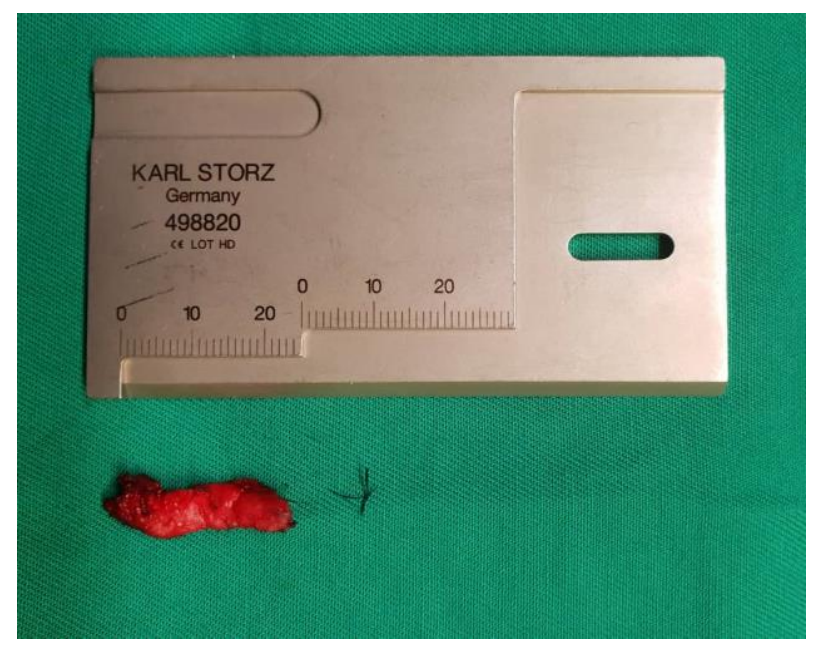

Figure 3: Specimen of epithelial lined sinus tract with a tuft of hair.

\section{DISCUSSION}

Without a doubt, pilonidal sinus is associated typically over the post anal region with few literature reports of the sinus occurring elsewhere. Previous authors have debated on its etiology of being either congenital or acquired. Recent evidence proves that pilonidal sinus is indeed a primary infection in origin triggered by the foreign body reaction exerted by the penetration of hair. ${ }^{5,6}$ This is further supported by a few cases reported by Patey and Scarfe of a pilonidal sinus over the barber's hand. They also concluded that in favour of pilonidal sinus is an acquired infective condition which involved two phases in its development; an initial phase in which the organism is introduced into the tissue giving rise to the infection leading to sinus formation and the entrance of hair into the sinus to allow the foreign body granulomatous reaction. Roger Brearly proposed that the pilonidal sinus 
over the gluteal cleft is produced by hair puncturing the intact skin and the subsequent negative pressure that developed further suck hair into the sinus aided by lateral movements of the buttocks. ${ }^{6}$ With regards to the nose, it is obvious that there is no stiff hair and no such negative suction can be introduced over the nasal pyramid. In our case, the sinus developed following a local trauma by an organic matter that the patient sustained over the nasal dorsum. It is likely that a foreign body reaction has taken place which created the sinus and that the hair enters the tract by being sucked into it as suggested by Patey, Scarce and Brearly. ${ }^{5,6}$ Diagnosis of a pilonidal sinus is based primarily on the history and examination of the site. Microscopic examination will often show a sinus tract lined by stratified squamous epithelium, a fragmented hair shafts within the tract and occasional fibrous and granulomatous lesion surrounding the tract. ${ }^{4,6}$ The treatment of the sinus involved primarily complete excision and the prevention of further hair insertion by means of advancing flap operation. The latter ensures the sinus to heal adequately and prevent recurrence. More famously, Karadakis described an advancement flap used to repair the wound, which reduced the depth of the wound and reduced hair accumulation and in turn reduced mechanical irritation. His method reported a recurrence rate of $1 \% .^{7}$ The main priority in the treatment is to secure healing of a chronic discharging sinus and to avoid recurrence. Treatment options depend on the preferences of the surgeon and patients consent. Although pilonidal sinus in the head and neck region is uncommon it should be included in the differentials to aid in the management of the disease.

\section{CONCLUSION}

It is uncommon for a sinus to develop over the nose more so a pilonidal sinus. History and direct examination which revealed a hair within a sinus are usually diagnostic. Histopathological examination supports the diagnosis.

\section{Funding: No funding sources \\ Conflict of interest: None declared \\ Ethical approval: Not required}

\section{REFERENCES}

1. Paulose KO, al Khalifa S, Raj SS, Saeed T. Pilonidal sinus of the nose. J Laryngol Otol. 1989;103(12):1210-3.

2. Sreedharan S, Kamath PM, Hegde MC, Lobo FD. Pilonidal sinus of nose-a diagnostic dilemma. Jurnalul de Chirurgie. 2010;6:343-7.

3. Junaid M, Ahmed SQ, Kazi M, Ali NS. Pilonidal sinus involving the nasal bridge: a rare manifestation. BMJ Case Rep. 2015;2015: bcr2015209948.

4. Patey DH Scarf RW. Pathology of post-anal pilonidal sinus: its bearing on treatment. Lancet. 1946;2:484-7.

5. Patey DH, Scarf RW. Pilonidal sinus in a barber's hand: with observation on post-anal pilonidal sinus. Lancet. 1948;2:13-8.

6. Brearley R. Pilonidal sinus - a new theory of origin. Br J Surg. 1955;43:62-7.

7. Karydakis GE. Easy and successful treatment of pilo-nidal sinus after explanation of its causative process. Aust N Z J Surg. 1992;62:385-9.

Cite this article as: Zulkifli FB, Zahedi FDB, Nordin AB, Jeing YD. Nasal supratip pilonidal sinus: a rare manifestation. Int J Otorhinolaryngol Head Neck Surg 2019;5:1394-6. 